\title{
ANÁLISE DA QUALIDADE DO CRESCIMENTO ECONÔMICO NA REGIÃO DE INTEGRAÇÃO DO BAIXO AMAZÔNAS BASEADA NA TEORIA DO CRESCIMENTO PRÓ-POBRE
}

\author{
Rhayza Alves Figueiredo de Carvalho1 \\ Abner Vilhena de Carvalho ${ }^{2}$ \\ Mario Tanaka Filho ${ }^{3}$ \\ Rodolfo Maduro Almeida 4 \\ Jarsen Luis Castro Guimarães ${ }^{5}$
}

\section{INTRODUÇÃO}

A Região de Integração do Baixo Amazonas (RIBA) é composta por 13 municípios, que apresentam características semelhantes, dentre os quais são de extrema importância pois envolvem uma dinâmica econômica, social e ambiental que compõem o Estado do Pará como um todo. Desse modo, a identificação de potencialidades e desafios se torna imprescindível para o desenvolvimento do Estado (bem estar), principalmente para subsidiar a identificação de áreas prioritárias para elaboração de políticas públicas.

O desenvolvimento gera melhorias socioeconômicas que desencadeiam aumento nos padrões de vida e também nos níveis de bem estar da população, desse modo, uma das preocupações mais relevantes das autoridades governamentais deve ser programar ações de políticas que resultem nos referidos benefícios sociais. Um das vertentes que envolvem esse processo é o econômico que contribui para a mobilidade dos estratos da população com menores níveis e na interrupção de fenômenos como a pobreza e distribuição de renda.

Salienta Souza (1997, p. 28) que o "desenvolvimento econômico era definido pelo aumento continuo dos níveis de vida incluindo maior consumo de produtos e de serviços básicos para o conjunto da população". Nesse sentido, estudar essa tríade se deve principalmente em verificar como essas variáveis se relacionam e geram impactos entre si, tanto positivos quanto negativos, possibilitando compreender a dinâmica social e investigação de novos rumos à seguir para mudanças no cenário do Brasil e regiões.

A íntima relação entre crescimento, desigualdade e pobreza pode ser comprovada pela própria dinâmica que o sistema econômico capitalista foi desencadeado, seguido de eficiência na produção de bens, entretanto, ocasionando males sociais e ambientais, com rápido crescimento

\footnotetext{
1 Bacharela em Economia pela UFPA. Mestra pelo PPGCS da UFOPA. E-mail: carvalho.rhayza@gmail.com

2 Doutor em Ciências Ambientais pelo PPGSND da UFOPA. Docente no PCEDR, no PPGCS da UFOPA. E-mail: abnervilhena@hotmail.com

3 Doutor em Engenharia Mecânica pelo CPPE/UFRJ. Docente no PPGCS da UFOPA. Email: tanakafi@gmail.com

4 Doutor em Computação Aplicada pelo INPE. Docente no PPGCS da UFOPA. E-mail: rodolfomaduroalmeida@gmail.com

5 Doutor em Desenvolvimento Sustentável do Trópico Úmido pelo NAEA/UFPA. Docente no PCEDR, no PPGCS e no PPGSND da UFOPA. E-mail: jarsen@bol.com.br
} 
impulsionado por empresas modernas que tendem a serem concentradoras e excludentes. Portanto, a interação entre essas três variáveis dá as condições necessárias para se diagnosticar em que magnitude o aumento da renda ou a redução da desigualdade impactam a redução da pobreza (ARAÚJO, 2009).

Nesse contexto, o conceito de desenvolvimento emerge como forma de minimizar desigualdades que foram acumuladas ao longo do tempo, segundo Sachs (2008, p.13) que salienta "[...] criando uma conexão capaz de preencher o abismo civilizatório entre as antigas nações metropolitanas e a sua antiga periferia colonial, entre ricas modernidades e a maioria ainda atrasada e exausta dos trabalhadores pobres".

O pensamento econômico que envolve somente a maximização do $\mathrm{PIB}$, ou seja, do crescimento econômico, é redutor e não abrange aos objetivos que se referem ao processo de desenvolvimento, como a promoção de igualdade, gerando oportunidades aos que vivem em piores condições, e logo reduzindo o nível de pobreza, fenômeno que se faz presente no mundo de grandes riquezas. A presença de equidade, de modo a dispensar o tratamento desigual aos indivíduos desiguais e solidariedade tanto com a geração atual quanto para as futuras, acrescentando uma sustentabilidade tanto social quanto ambiental ao conceito, e ajudando aos indivíduos mais fracos e incluindo ações para tal (SACHS, 2008).

Nesse contexto, o uso dos métodos quantitativos para analisar o cenário social das regiões brasileiras é de extrema relevância, como ferramenta de diagnóstico e de planejamento, contribuindo, principalmente para o avanço do conhecimento científico. Apesar dos estudos quantitativos, como técnicas de estatística descritiva e inferencial serem limitados nas áreas das Ciências Sociais (SANTOS; COUTINHO, 2002).

Desse modo, o problema de pesquisa a ser investigado no trabalho é: Qual é a situação socioeconômica na Região de Integração do Baixo Amazonas, assim como a qualidade do crescimento nessa região? Portanto, o objetivo deste ensaio é analisar a qualidade do crescimento da RIBA, e se este tem sido um crescimento pró-pobre. Desdobra-se, ainda em objetivo a análise evolutiva dos indicadores de crescimento econômico, pobreza e desigualdade nos municípios da RIBA

\section{DESENVOLVIMENTO ECONÔMICO NA PERSPECTIVA INCLUDENTE E A TEORIA DO CRESCIMENTO PRÓ-POBRE}

A relação entre crescimento econômico e as melhorias das dimensões sociais e ambientais que contribuem para o desenvolvimento podem ser harmoniosas ou não, revelando situações em 
que esses elementos são conflitantes, sendo fundamental importância administrar os aspectos não somente quantitativos como qualitativos para atingir melhorias sustentáveis e de bem-estar de uma sociedade (THOMAS et al., 2002).

A teoria econômica passou a distinguir o crescimento econômico da ideia de desenvolvimento, e nas décadas de 1950 e 1960, foi difundida a teoria trickle-down, que salienta os benefícios do crescimento expandidos por todos os segmentos da sociedade. Dessa maneira, era caracterizado como benéfico para os pobres qualquer aumento em suas rendas, mesmo que seja inferior ao ganho médio da sociedade e de forma semelhante um aumento do PIB seria sempre acompanhado de redução na pobreza (PINTO; OLIVEIRA, 2010).

Nesse sentido, uma das vertentes conhecida como fundamentalista de mercado, acredita que a ideia de desenvolvimento é redundante, ou seja, o mesmo seria naturalmente resultado do crescimento econômico como um "efeito cascata". Dessa maneira, Sachs (2008, p. 26) afirmava que:

\footnotetext{
A teoria do efeito cascata seria totalmente inaceitável em termos éticos, mesmo se funcionasse, o que não é o caso. Num mundo de desigualdades abismais, é um absurdo pretender que os ricos devam ficar mais ricos ainda, para que os destituídos possam ser um pouco menos destituídos.
}

Nesse contexto, vários estudiosos ampliaram suas análises sobre desenvolvimento econômico, considerando não só em termos de crescimento do PIB, mas principalmente destacando a igualdade de oportunidades de acesso aos serviços públicos assim como políticas de emprego, mediante a criação de oportunidades de trabalho decente, que gera renda aos indivíduos e viabiliza uma solução duradoura ao problema social. Segundo Sachs (2008, p. 38) "A maneira natural de se definir o desenvolvimento includente é por oposição ao padrão de crescimento perverso, conhecido como excludente, (do mercado de consumo) e concentrador (de renda e riqueza)".

Historicamente, os países desenvolvidos apresentam, em geral, grandes vitórias no que se refere à melhoria da qualidade de vida, sendo por uma maior expectativa de vida, saúde e educação ou por novas oportunidades e liberdades, que expandem a capacidade de delineamento de seu próprio futuro, entretanto, nos países que ainda caminham para essa conjuntura, a distância entre os pobres e ricos se torna cada vez maior (THOMAS et al., 2002).

A qualidade de crescimento se refere aos aspectos essenciais que delineiam este processo e que também acrescentam aos seus resultados. Nos países em desenvolvimento, destacam-se três princípios que acentuam essa qualidade, os valores principais: capital físico, capital humano (social), em que, a educação exerce papel preponderante e capital natural, que deve ser usado eficientemente devido sua importância para a saúde humana e para populações 
que dependem de recursos naturais para a sobrevivência. O segundo princípio são os aspectos distributivos, logo, para que o crescimento reduza a pobreza os benefícios devem ser amplamente distribuídos e estáveis. E por fim, um governo estruturado, para isso, se deve investir em capacidade, como o funcionamento de burocracias, estruturas reguladoras, liberdades civis e instituições responsáveis e transparentes (THOMAS et al., 2002).

É fato notável que o crescimento econômico acontece de maneira desigual entre as regiões e países do mundo, caracterizados como desenvolvidos ou não, a qualidade afeta diretamente os resultados do desenvolvimento, a maioria não usufrui dos benefícios que esse processo desencadeia, sendo assim, crucial explorar as complexas interações dos fatores que delineiam o crescimento.

Nesse âmbito, analisar a origem pelo qual o crescimento se obtém é imprescindível, já que alguns fatos comprovam a existência de uma relação direta entre crescimento econômico e avanços sustentáveis no bem-estar, além do mais, mostra-se relacionado positivamente com a redução da pobreza, contudo, alguns exemplos mostram-se contrários, já que estagnam ou reduzem as dimensões sociais e de bem-estar e também se relacionam negativamente com os níveis de pobreza (THOMAS et al., 2002).

No que diz respeito a inter-relação entre o crescimento econômico e a redução nos níveis de pobreza, Berardi e Marzo (2015, p. 14) atentam que:

\footnotetext{
O impacto do crescimento econômico sobre a redução da pobreza depende da medida em que o crescimento é inclusivo e beneficia os pobres, o que mostrou variar de acordo com a estrutura da economia o mecanismo subjacente é o crescimento em setores em que muitas pessoas pobres trabalham é mais propenso a reduzir a pobreza.
}

A importância de políticas efetivas associados ao desenvolvimento pode ser comprovada principalmente ao longo das décadas de 60 e 90, devido as ampliações de medidas do desenvolvimento humano, especialmente nas dimensões de longevidade e conhecimento. Entretanto, demais aspectos qualitativos da vida foram modestos dentre os quais, redução da pobreza, ganhos igualitários e qualidade ambiental (THOMAS et al., 2002).

Como resultado da busca incessante dos países pelo crescimento econômico, os dois principais problemas herdados do século passado - apesar de seu progresso científico e técnico sem precedentes estão, o desemprego em massa e as desigualdades crescentes (SACHS, 2008).

Ao longo do tempo vários pensamentos sobre a relação de crescimento e distribuição de renda foram desencadeados. Existem controvérsias entre vantagens e desvantagens atribuídas ao crescimento econômico se obtivesse uma melhor distribuição de renda, logo, a problemática 
da distribuição de renda, poderia ser fator preponderante para se ter desenvolvimento, de modo, que a agregação entre crescimento e distribuição de renda ocasionaria tal condição. Conforme Barreto (2005, p. 03) "uma das mais importantes metas em desenvolvimento econômico é 0 esforço em reduzir a pobreza que pode ser acompanhado por crescimento econômico e/ou redistribuição da renda".

Alguns modelos destacam que o crescimento impulsionado por determinado setor econômico só pode ser persistente se os benefícios inicias forem repartidos homogeneamente promovendo expansão e aprofundamentos dos mercados, outras modelagens destacam uma relação inversa, na qual uma diminuição do crescimento gera maior desigualdade de renda.

Em 1954, Simon Kuznets formulou uma hipótese de acordo com as evidências empíricas do período, conhecido como a "Curva do 'U' invertido" em que mostra a necessidade de economias inicialmente crescerem, e se desenvolverem para depois distribuí-las entre os indivíduos, diminuindo assim, a desigualdade de renda. Quarenta anos depois alguns pensadores verificaram que a estrutura da distribuição de renda era imensamente rígida independentemente do tipo de crescimento econômico. Em 1993, Douglas North destacou a qualidade das instituições de cada sociedade, já que mostram as crenças de seu povo, para 0 processo de desenvolvimento (VEIGA, 2010).

A desigualdade de renda brasileira possui algumas particularidades, que as distinguem dos padrões de renda observados em outros países, inclusive nos denominados em desenvolvimento, dentre as quais se destacam a magnitude relativa da desigualdade, tratandose do grau de riqueza interna ou quanto a sua posição em relação aos países com condições socioeconômicas semelhantes, outra questão é a persistência da desigualdade, que apresenta uma certa estabilidade ao longo do tempo apesar de diversas alterações na economia, e por fim, é que a desigualdade se concentra na cauda superior da distribuição, particularmente em favor dos 10\%, ou último décimo mais ricos da população, dessa forma a persistência se dá devido a uma melhor condição dos mais ricos e não uma pior situação dos pobres (DINIZ, 2005).

Vale ressaltar que outras características contribuem de tanto direta quanto indiretamente para a desigualdade, particularmente no cenário econômico e que ajuda na definição da distribuição de renda, como o funcionamento do mercado de trabalho e as questões relativas à existência de discriminação por gênero, segmentações tanto espacial, quanto por posição, ocupação e ramo de atividade (DINIZ, 2005).

A partir da característica de desigualdade de renda brasileira, denota-se um vínculo direto entre desigualdade e pobreza, da qual derivam três elementos indissociáveis, o primeiro é que 0 país não é uma nação pobre, porém apresenta grande quantidade de pobres, no qual a origem 
da pobreza não corresponde na escassez dos recursos, o segundo é que a força da pobreza está associada à concentração de renda, tal inferência resulta do fato que a renda per capita e mesmo a renda média, especialmente essa última é bastante superior à renda que define a linha de pobreza e por fim, em consequência aos dois fatores anteriores, pressupõem se que a distribuição equitativa seria o suficiente para eliminar a pobreza (BARROS; HENRIQUES; MENDONÇA, 2000; ROCHA, 2003; DINIZ, 2005).

O crescimento econômico de qualidade é aquele que reduz a pobreza e a desigualdade. Contudo, a situação de pobreza em países como o Brasil, segundo Costa e Miranda (2008, p. 03) "está relacionada ao nível de desigualdade e ao modelo de desenvolvimento excludente, o qual surge renovado em cada período histórico".

Sabemos que o crescimento econômico, mesmo que seja acentuado, não traz desenvolvimento (socioeconômico) a menos que gere emprego e contribua para a redução da pobreza e das desigualdades (THOMAS et al., 2002). Nessa perspectiva, o conceito de crescimento "pró-pobre" está associado ao aumento da renda dos pobres comparativamente à renda dos não-pobres durante um período de tempo específico. Apesar da distinção conceitual, compreendemo-lo como aquele que habilita os pobres a participarem da geração do crescimento econômico e usufruto dos seus resultados (GONÇALVES; SILVEIRA NETO, 2007).

De forma mais ampla, a teoria do crescimento pró-pobre está diretamente integrada à perspectiva do desenvolvimento econômico includente, o qual se utiliza da precedência do crescimento como fenômeno de importante participação na geração de riqueza e bem estar. Dessa forma, "o crescimento é pró-pobre quando absorve mão de obra e é acompanhado por políticas e programas que diminuem as desigualdades e facilitam a geração de emprego e renda para os pobres, particularmente mulheres e outros grupos tradicionalmente excluídos [...]" (KAKWANI; PERNIA, 2000, p. 01). Ou seja, a qualidade do crescimento, em sua vertente econômica, se traduz em desenvolvimento econômico, quando a resultante daquele fenômeno gera este último, entremeado por sua vez na diminuição da pobreza e da desigualdade (SACHS, 2008; VEIGA, 2005; 2010).

\subsection{CRESCIMENTO PRÓ-POBRE E AS ELASTICIDADE RENDA-POBREZA E DESIGUALDADE-POBREZA}

$O$ crescimento pró pobre é um termo cunhado da inter-relação entre crescimento, desigualdade e pobreza e, diz respeito, sobretudo, a classe menos abastada da sociedade (KAKWANl; KHANDER; SON, 2004). 
Dentro do contexto das políticas de combate à pobreza, Barreto $(2005$, p. 04$)$ destaca "ser importante termos em mente que toda discussão a respeito das políticas que deveriam ser utilizadas para reduzir a pobreza deve ter como elemento chave à definição do que venha ser crescimento 'pró-pobres'”.

Além do mais a construção do debate acerca do crescimento econômico pró pobre e, especialmente acerca de suas análises é importante ressaltar que estes partem de uma questão fundamental, as quais Barreto $(2005$, p, 04) desencadeia em forma dos seguintes questionamentos: "o que é reduzir significativamente a pobreza? Em que nível os pobres deveriam se beneficiar do crescimento econômico para que ele seja considerado 'pró-pobres?' Políticas 'pró-pobres' são sensíveis às medidas de pobreza utilizadas?"

Sabendo que existe mais de um único conceito do que é o crescimento pró-pobre (PINTO; OLIVEIRA, 2010), para se ter uma resposta consistente aquelas questões, como descrito em Barreto (2005, p. 04) "podemos considerar quatro visões do problema que se complementam", assim descritas:

Em uma primeira abordagem consideraremos crescimento "pró-pobres" se a participação da renda dos mais pobres da população crescer mais que proporcionalmente ao crescimento da renda média da economia, o que implicaria, neste caso, que a desigualdade cairia com 0 crescimento.

Para uma segunda definição, atribuída a White e Anderson (2001), a participação dos pobres na renda cresceria pelo menos tão quanto à participação de sua população. Isso implicaria que a renda per capita dos mais pobres tenderia a aumentar, o que implicaria numa queda da desigualdade absoluta.

E por último tem-se a definição, proposta por Kalkwani e Pernia (2000), dever-se-ia fazer uma comparação de mudanças na pobreza devido ao crescimento econômico (mantendo a desigualdade constante) e mudanças na pobreza devido a alterações reais na desigualdade. Os autores avaliam o crescimento ser "pró-pobres" a partir da relação entre esses dois índices, necessitando para tal que ele seja maior que a unidade.

Por fim, numa abordagem mais simples da questão, crescimento "pró-pobres" é analisado apenas focando-se a relação entre pobreza e crescimento. Neste caso ele pode ser considerado dessa forma se simplesmente for capaz de reduzir a pobreza para uma determinada medida préestabelecida independente do que ocorre com o nível de desigualdade (RAVALLION; CHEN, 2003). Desta forma, utilizando-se esse conceito, um episódio de crescimento não será considerado "pró-pobres" somente se a renda dos mais pobres ficar estagnada ou mesmo se reduzir. 
Além das quatros visões acima citadas, Kakwani, Khander e Son (2004) argumentam que pode-se classificar o crescimento pró-pobre de duas maneiras: (i) segundo a definição fraca ou forte e/ou; (ii) segundo o enfoque parcial ou completo.

A definição fraca de crescimento pró-pobre é aquela que consiste da teoria do trickledown ${ }^{6}$, que classifica como vantajoso para os pobres qualquer aumento de suas rendas, mesmo que seja inferior ao ganho médio da sociedade. A definição forte pode ser subdividida em crescimento pró-pobre relativo ou absoluto: $O$ conceito relativo indica 0 crescimento econômico que melhora a situação dos pobres proporcionalmente mais do que a dos não pobres, implicando redução na desigualdade relativa de renda. Por outro lado, a definição absoluta engloba aqueles casos em que os pobres recebem os benefícios monetários em maior quantidade que o resto da população, sendo também denominada "super pró-pobre". Segundo o enfoque parcial classifica as condições sob as quais o crescimento pode ser considerado própobre ou antipobre, mas não especifica nenhuma linha ou indicador de pobreza, ao passo que no enfoque completo, por sua vez, permite sempre obter resultados conclusivos sobre se um processo de crescimento é ou não pró-pobre (PINTO; OLIVEIRA, 2010).

Entendendo por elasticidade o impacto da variação de $1 \%$ de uma variável (independente/explicativa) em outra (dependente/explicada) (RAVALLION, 2001), denota-se que para avaliar a sensibilidade da pobreza em relação ao crescimento e à desigualdade, incluindo, define-se elasticidade total em duas elasticidades parciais (PERNIA, 2003; SANTOS, 2012), a saber:

i) Elasticidade parcial renda-pobreza: Mede o "efeito crescimento puro", isto é, o efeito do crescimento sobre a redução da pobreza, na medida em que considera apenas 0 impacto da variação da renda sobre a pobreza, sob um contexto de desigualdade inalterada.

ii) Elasticidade parcial desigualdade-pobreza: Mede o "efeito distribuição puro", ou seja, o efeito da distribuição de renda sobre a pobreza. Nesse sentido, considera somente o impacto da variação da distribuição de renda sobre a pobreza, em um contexto de estabilidade do nível de renda.

Várias pesquisas tentam explicar a efetividade do crescimento para reduzir a pobreza e desigualdade, utilizando alguns métodos quantitativos que mensuram a relação entre crescimento, desigualdade e pobreza. Nesse sentido destacam-se estudos que examinaram 0 Crescimento Pró-Pobre no Brasil.

\footnotetext{
6 Pensamento (mainstraim) amplamente difundido no pensamento econômico sobre o desenvolvimento, exercendo papel dominante durante as décadas de 1950 e 1960, ancorada no ideal de que os benefícios do crescimento se espalhavam automaticamente por todos os segmentos da sociedade, ou seja, que 0 aumento do PIB vem sempre acompanhado de redução da pobreza (PINTO; OLIVEIRA, 2010).
} 
Manso, Barreto e Tebaldi (2006) verificaram os efeitos do crescimento econômico sobre a renda dos pobres no período de 1995 a 2004, utilizando a metodologia de Kraay (2004) e Datt e Ravallion (1992), os resultados mostraram que os componentes de crescimento da renda média e de sua distribuição são suficientes para explicar a maioria das variações nos níveis de pobreza entre os Estados brasileiros, e que o crescimento econômico tem sido o principal instrumento de combate à pobreza no Nordeste.

Resende (2008) verificou que o efeito do crescimento econômico nos municípios mineiros apresentou-se heterogêneo em relação a sua qualidade, no período de 1991 e 2000. Utilizando as propostas metodológicas de Ravallion e Datt (1999) e posteriormente de Kakwani e Pernia (2000) e Son (2004). Nas macrorregiões Sul e Alto Paranaíba observou-se uma relativa maior "qualidade" de crescimento econômico, já que maior parte dos municípios apresenta crescimento pró-pobre, ou seja, maior elasticidade "pobreza-crescimento". Enquanto que nos municípios do Norte e Noroeste do Estado apresentou-se inverso.

Gonçalves (2010) verificou a qualidade do crescimento nos Conselhos Regionais de Desenvolvimento (COREDES) do estado do Rio Grande do Sul, no período de 2000 a 2006. A partir da metodologia desenvolvida nos estudos de Ravallion e Datt (2002) e de Son (2004), que mostrou um crescimento pró-pobre de maneira heterogênea, dentre os quais existem nove COREDES na região Norte tinham crescimento pró-pobre. Na região Sul apenas três COREDES.

Enquanto, Pinto e Oliveira (2010) estudaram o crescimento pró-pobre nas 27 unidades federativas do Brasil entre 1995 e 2007. Utilizando-se as metodologias de Datt e Ravallion (1992), Ravallion e Chen (2003) e Bourguignon (2002) analisando o desempenho dos estados. Os resultados mostraram que dinâmica entre crescimento e pobreza ocorre de maneira significativamente distinta ao longo dos estados e das regiões do Brasil, dentre as quais as regiões Sul, Sudeste e Centro-Oeste têm os melhores desempenhos nas análises subnacionais do crescimento pró-pobre. As UFs da região Nordeste e Norte geralmente se situam nas últimas posições, demonstrando que a redução da desigualdade exerce um papel essencial na busca de um padrão de crescimento cada vez mais pró-pobre.

Bezerra et al. (2010) analisaram se relação entre o crescimento econômico e pobreza no estado de Alagoas têm sido pró-pobre no período de 1991 e 2000, usando a metodologia de Ravallion e Datt (1999) e de Son (2004), nas quais nenhuma microrregião apresentou crescimento pró-pobre, sete microrregiões e a mesorregião do Sertão Alagoano apresentaram crescimento empobrecedor, ou seja, um crescimento econômico positivo que aumenta a pobreza. Já nas outras seis microrregiões e nas mesorregiões Leste Alagoano e Agreste 
Alagoano assim, como no estado de forma geral apresentaram resultados inconclusivos, desse modo, os mais pobres não se beneficiaram com o crescimento econômico.

Silveira Neto (2014) verificou se o crescimento da renda na região Nordeste, em seus estados e nas 42 mesorregiões pode ser considerado pró-pobre durante os períodos 1991-2000 e 2000-2010, considerando a renda do trabalho e a renda de todas as fontes. Utilizando a proposta metodológica de Kakwani (2000). Os resultados obtidos indicaram que na renda de todas as fontes, no período 1991-2000 o crescimento da renda no Nordeste, na maioria da área de estudo não pode ser considerado pró-pobre, enquanto que em 2000-2010, o crescimento é generalizadamente pró-pobre. Contudo, os resultados a partir da renda do trabalho, no período 1991-2000, mostraram que todos os estados e a grande maioria das mesorregiões apresentam crescimento empobrecedor. Em relação ao período 2000 e 2010, as evidências obtidas indicam que as mesorregiões apresentam desempenhos mais favoráveis.

Os trabalhos de Godoy e Rodrigues (2017), Oliveira e Jacinto (2015), Netto Junior e Figueiredo (2014) corroboram para o diagnóstico de que em geral, a dinâmica entre crescimento e pobreza ocorre de maneira distinta ao longo dos estados e das regiões do Brasil, dentre as quais as regiões Sul, Sudeste e Centro-Oeste têm os melhores desempenhos nas análises do crescimento comparativamente as regiões Norte e Nordeste. Contudo, percebe-se que com 0 passar dos anos existe uma tendência para melhorar a qualidade do crescimento nessas regiões beneficiando principalmente as populações mais pobres do país. Desse modo, as análises efetuadas no sentido de verificar a qualidade do crescimento e suas devidas contribuições em regiões com maiores níveis de pobreza são de essenciais para a análise da qualidade de vida em sociedade.

\section{CARACTERIZAÇÃO, EVOLUÇÃO, ANÁLISE DOS INDICADORES E A DESCRIÇÃO DO MODELO EMPÍRICO}

Conforme Fapespa (2017) a Região de Integração do Baixo Amazonas é composto por treze municípios, que são: Alenquer, Almeirim, Belterra, Curuá, Faro, Juruti, Mojuí dos Campos, Monte Alegre, Óbidos, Oriximiná, Prainha, Santarém e Terra Santa como mostra a Figura 1: 
Figura 1 - Mapa da Região de Integração do Baixo Amazonas

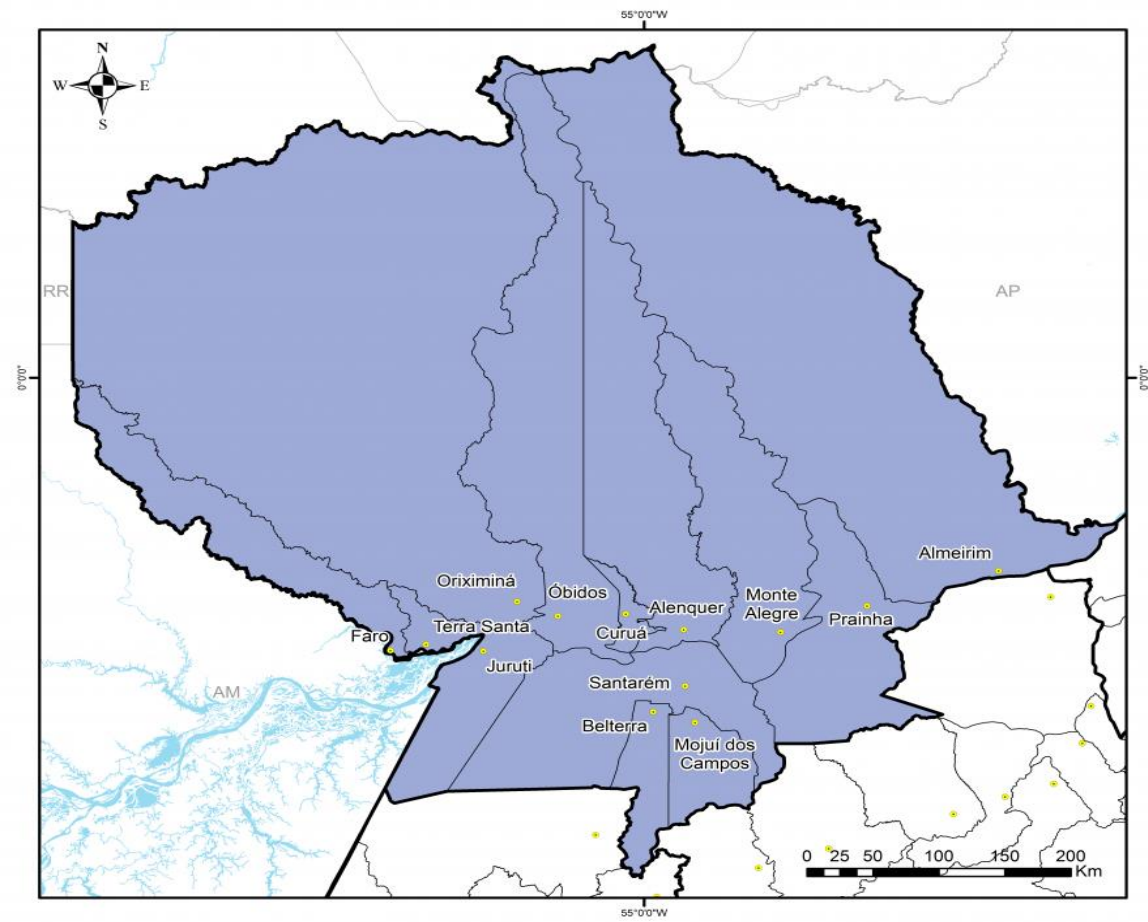

Fapespa PAVERNo

REGIÃO DE INTEGRAÇÃO BAIXO AMAZONAS
- ESTADO DO PARÁ

CONVENÇŌES CARTOGRÁFICAS - Sedes Municipais
Unidades Federativas Unidades Federativa $\simeq$ Limite da Regiåo de Integraçáa 3 Hidrografia

REGIĀO DE INTEGRAÇĀO $\square$ Baixo Amazonas

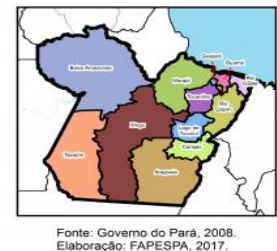

Fonte:

FAPESPA

(2017)

disponível

em

$<$ http://www.fapespa.pa.gov.br/sistemas/radar2017/mapas/01_territorio/regiao_de_integracao_baixo_amazonas.png $>$ acesso em 05/09/2019.

Vale ressaltar que o município de Mojuí dos Campos foi integrado à Região de Integração do Baixo Amazonas no ano de 2012, e por isto não foi incorporado nas análises do estudo.

Em 2014 a área aproximada da Região de Integração do Baixo Amazonas era em torno de 315,86 mil km², o que corresponde a $25 \%$ da área total do Estado do Pará, e sua população equivalia a 770.275 habitantes. As atividades econômicas que possuem destaque na região são as que se relacionam com a mineração, o agronegócio, a agricultura familiar e o turismo, sendo que este último tem como base principal o turismo ecológico, uma vez que a mesorregião possui muitos atrativos naturais, como praias e belas paisagens (BRASIL, 2012).

Utilizando-se os dados censitários disponibilizados no Atlas do Desenvolvimento Humano nos anos de 1991, 2000 e 20107, construiu-se a base de dados a partir das proxies dos indicadores de crescimento (renda per capita média e dos percentis mais pobre e mais ricos da distribuição de renda); da desigualdade (percentual da renda apropriada pelos $20 \%$ mais pobres e mais ricos, percentual da renda apropriada pelos 10\% mais ricos, razão 10/40 e 20/40 dos mais ricos e mais pobres da distribuição e, do índice de Gini); e da pobreza (a proporção de pobres e a renda per capita dos pobres).

${ }^{7}$ Os dados podem ser acessados no endereço: http://atlasbrasil.org.br/2013/pt/consulta/. 
Desta maneira, verifica-se a evolução dos indicadores de crescimento econômico, desigualdade e pobreza. A nível municipal, a Tabela 1 mostra a evolução da renda per capita na RIBA, em que as três maiores rendas per capita são verificadas em Almeirim nos três períodos analisados, seguido de Oriximiná e Santarém para o ano de 1991. Em 2000 e 2010, os municípios com segunda e terceira maiores rendas foram Santarém e Oriximiná, e Santarém e Terra Santa, respectivamente. E, apresentando uma maior variação percentual relativa os municípios de Terra Santa, Faro e Santarém.

\section{Tabela 1- Evolução da Renda per capita na RIBA}

\begin{tabular}{|c|c|c|c|c|c|c|}
\hline Espacialidade & $\begin{array}{l}\text { Renda per } \\
\text { capita (1991) }\end{array}$ & $\begin{array}{l}\text { Renda per } \\
\text { capita (2000) }\end{array}$ & $\begin{array}{l}\text { Renda per } \\
\text { capita (2010) }\end{array}$ & $\begin{array}{c}\Delta \\
(1991-2000)\end{array}$ & $\begin{array}{c}\Delta \\
(2000-2010)\end{array}$ & $\begin{array}{c}\Delta \\
(1991-2010)\end{array}$ \\
\hline Alenquer & 143,85 & 165,11 & 215,33 & 0,1478 & 0,3042 & 0,4969 \\
\hline Almeirim & 296,99 & 486,59 & 484,16 & 0,6384 & $-0,0050$ & 0,6302 \\
\hline Belterra & 126,00 & 121,84 & 241,57 & $-0,0330$ & 0,9827 & 0,9172 \\
\hline Curuá & 110,15 & 122,71 & 180,94 & 0,1140 & 0,4745 & 0,6427 \\
\hline Faro & 76,32 & 130,14 & 180,47 & 0,7052 & 0,3867 & 1,3646 \\
\hline Juruti & 129,92 & 108,66 & 241,39 & $-0,1636$ & 1,2215 & 0,8580 \\
\hline Monte Alegre & 149,37 & 181,61 & 231,65 & 0,2158 & 0,2755 & 0,5508 \\
\hline Óbidos & 157,66 & 162,15 & 255,03 & 0,0285 & 0,5728 & 0,6176 \\
\hline Oriximiná & 217,15 & 264,69 & 332,29 & 0,2189 & 0,2554 & 0,5302 \\
\hline Prainha & 120,38 & 121,01 & 193,32 & 0,0052 & 0,5976 & 0,6059 \\
\hline Santarém & 204,43 & 279,01 & 409,07 & 0,3648 & 0,4661 & 1,0010 \\
\hline Terra Santa & 117,85 & 154,11 & 338,44 & 0,3077 & 1,1961 & 1,8718 \\
\hline
\end{tabular}

Fonte: Elaboração própria com base nos censos censitários - Atlas do Desenvolvimento Humano no Brasil

$\mathrm{Na}$ Tabela 2, encontra-se evolução do índice de desigualdade de renda (Gini) nos munícipios da RIBA, dentre os quais apresentam maior desigualdade de renda, no ano de 1991, estão os municípios de Almeirim, Oriximiná e Santarém. No ano de 2000, novamente, apresentaram maiores índice de desigualdade de Almeirim, Oriximiná, Santarém mas com a inclusão de Juruti. E no último período, ano de 2010, estão Prainha, Almeirim, Oriximiná. Os municípios que apresentam maior variação do índice de desigualdade de renda (Gini), são os municípios de Prainha, Curuá e Faro. Ou seja, nesses municípios os níveis de desigualdade aumentaram, em aproximadamente $58 \%, 40 \%$ e $27 \%$, respectivamente.

Tabela 2- Evolução do índice de desigualdade de Renda (Gini) na RIBA 


\begin{tabular}{|c|c|c|c|c|c|c|}
\hline Espacialidade & $\begin{array}{l}\text { Índice de Gini } \\
\text { (1991) }\end{array}$ & $\begin{array}{l}\text { Índice de } \\
\text { Gini (2000) }\end{array}$ & $\begin{array}{l}\text { Índice de } \\
\text { Gini (2010) }\end{array}$ & $\begin{array}{c}\Delta \\
(1991-2000)\end{array}$ & $\begin{array}{c}\Delta \\
(2000-2010)\end{array}$ & $\begin{array}{c}\Delta \\
(1991-2010)\end{array}$ \\
\hline Alenquer & 0,51 & 0,56 & 0,58 & 0,0980 & 0,0357 & 0,1373 \\
\hline Almeirim & 0,63 & 0,72 & 0,65 & 0,1429 & $-0,0972$ & 0,0317 \\
\hline Belterra & 0,52 & 0,64 & 0,58 & 0,2308 & $-0,0938$ & 0,1154 \\
\hline Curuá & 0,43 & 0,57 & 0,60 & 0,3256 & 0,0526 & 0,3953 \\
\hline Faro & 0,44 & 0,54 & 0,56 & 0,2273 & 0,0370 & 0,2727 \\
\hline Juruti & 0,52 & 0,61 & 0,59 & 0,1731 & $-0,0328$ & 0,1346 \\
\hline Monte Alegre & 0,51 & 0,60 & 0,59 & 0,1765 & $-0,0167$ & 0,1569 \\
\hline Óbidos & 0,51 & 0,54 & 0,59 & 0,0588 & 0,0926 & 0,1569 \\
\hline Oriximiná & 0,59 & 0,61 & 0,64 & 0,0339 & 0,0492 & 0,0847 \\
\hline Prainha & 0,43 & 0,57 & 0,68 & 0,3256 & 0,1930 & 0,5814 \\
\hline Santarém & 0,56 & 0,61 & 0,58 & 0,0893 & $-0,0492$ & 0,0357 \\
\hline Terra Santa & 0,49 & 0,54 & 0,58 & 0,1020 & 1,6734 & 0,1837 \\
\hline
\end{tabular}

Fonte: Elaboração própria com base nos censos censitários - Atlas do Desenvolvimento Humano no Brasil

$\mathrm{Na}$ Tabela 3 encontra-se o percentual de pobres nos munícipios da RIBA, dentre os quais apresentaram maior indicador de pobreza (proporção de pobres), no ano de 1991, estão os municípios de Faro, Terra Santa e Juruti. No ano de 2000, novamente, apresentaram maiores índice de desigualdade de Juruti, Faro, mas agora com a inclusão de Prainha. E no último período, ano de 2010, estão Prainha, Curuá e Faro. Os municípios da RIBA que apresentam maior variação da evolução do percentual de pobres nas três últimas décadas, são nos municípios de Terra Santa, Santarém e Faro. Ou seja, nestes municípios, o percentual de pobres diminuiu, em aproximadamente $51 \%, 48 \%$ e $39 \%$, respectivamente, mais do que nos outros municípios da Região de Integração do Baixo Amazonas.

Tabela 3- Evolução do Percentual de Pobres na RIBA

\begin{tabular}{|c|c|c|c|c|c|c|}
\hline Espacialidade & $\begin{array}{c}\% \text { de pobres } \\
\text { (1991) }\end{array}$ & $\begin{array}{c}\text { \% de pobres } \\
(2000)\end{array}$ & $\begin{array}{c}\% \text { de pobres } \\
\text { (2010) }\end{array}$ & $\begin{array}{c}\Delta \\
(1991-2000)\end{array}$ & $\begin{array}{c}\Delta \\
(2000-2010)\end{array}$ & $\begin{array}{c}\Delta \\
(1991-2010)\end{array}$ \\
\hline Alenquer & 71,97 & 67,77 & 52,34 & $-0,0584$ & $-0,2277$ & $-0,2728$ \\
\hline Almeirim & 51,49 & 48,37 & 38,3 & $-0,0606$ & $-0,2082$ & $-0,2562$ \\
\hline Belterra & 71,97 & 72,9 & 47,03 & 0,0129 & $-0,3549$ & $-0,3465$ \\
\hline Curuá & 71,4 & 74,95 & 61,12 & 0,0497 & $-0,1845$ & $-0,1440$ \\
\hline Faro & 90,64 & 76,74 & 55,62 & $-0,1534$ & $-0,2752$ & $-0,3864$ \\
\hline Juruti & 75,44 & 81,45 & 49,58 & 0,0797 & $-0,3913$ & $-0,3428$ \\
\hline
\end{tabular}




$\begin{array}{ccccccc}\text { Monte Alegre } & 70,09 & 62,99 & 51,73 & -0,1013 & -0,1788 & -0,2619 \\ \text { Óbidos } & 63,48 & 61,18 & 48,27 & -0,0362 & -0,2110 & -0,2396 \\ \text { Oriximiná } & 58,93 & 52 & 46,08 & -0,1176 & -0,1138 & -0,2181 \\ \text { Prainha } & 74,41 & 75,2 & \mathbf{6 7 , 2 3} & 0,0106 & -0,1060 & -0,0965 \\ \text { Santarém } & 59,5 & 49,55 & 31,07 & -0,1672 & -0,3730 & -\mathbf{0 , 4 7 7 8} \\ \text { Terra Santa } & \mathbf{7 8 , 0 3} & 65,71 & 38,14 & -0,1579 & -0,4196 & -\mathbf{0 , 5 1 1 2}\end{array}$

Fonte: Elaboração própria com base nos censos censitários - Atlas do Desenvolvimento Humano no Brasil

\subsection{DESCRIÇÃO DO MODELO EMPÍRICO: O MODELO LOG-LOG COM DADOS COMBINADOS (PAINEL)}

A metodologia utilizada neste trabalho enquadra-se de acordo com a definição forte de crescimento pró-pobre, em termos relativos e sob o enfoque completo. Ou seja, o crescimento pró-pobre é visto neste trabalho como um processo que deve, necessariamente, beneficiar os pobres. Em outras palavras, o crescimento pró-pobre é visto como um processo que deve, necessariamente, reduzir a pobreza e a desigualdade relativa de renda.

$\mathrm{Na}$ metodologia da elasticidade-renda da pobreza, optou-se por utilizar a lançada por Datt e Ravallion (1992) e descrita em Pinto e Oliveira (2010), com algumas adaptações aos objetivos do presente trabalho, sendo a principal delas a inclusão do coeficiente de Gini como variável explanatória no modelo, tal como feita por Pinto e Oliveira (2010). Tal feito, permite que o modelo capte a divisão, presente na literatura, da elasticidade total em duas elasticidades parciais da renda-pobreza e da desigualdade-pobreza.

O conceito de elasticidade total, segundo Pernia (2003), é dividido em 'efeito crescimento puro' e 'efeito distribuição'. A elasticidade parcial renda-pobreza corresponde ao efeito do crescimento puro sobre a redução da pobreza, ou seja, contempla-se apenas o impacto causado pela variação da renda sobre a pobreza, em um contexto de desigualdade inalterada. Adicionando o índice de Gini como mais uma variável explicativa no modelo, incorpora-se a elasticidade parcial desigualdade-pobreza, ou seja, o coeficiente angular referente a essa variável pode ser chamado de elasticidade-redistribuição da pobreza e, teremos o parâmetro do efeito distribuição.

A elasticidade foi obtida por meio de um modelo econométrico de regressão linear, sob a forma funcional, $\log _{-} \log ^{8}$, que possui a proporção de pobres $(P 0)$ como variável dependente e; a

\footnotetext{
8 Considere o seguinte modelo conhecido como modelo de regressão exponencial, que também pode ser expresso como: em que In = logaritmo natural (logaritmo com base $e$, em que $e=2,718$ ). Se escrevermos a Equação como em que $\alpha=\ln \beta_{1}$, este modelo é linear nos parâmetros $\alpha$ e $\beta_{2}$, linear nos logaritmos das variáveis $Y$ e $X$, e pode ser estimado mediante uma regressão de MQO. Devido a essa linearidade, tais modelos são denominados modelos log-log, duplo-log ou log-lineares (GUJARATI, 2006, p. 142; 2011, p. 176).
} 
renda familiar ou produto per capita (Yit), e o índice de Gini (Giniit) como variáveis explicativas do modelo, contemplando as variáveis em nível:

Onde:

$$
\begin{gathered}
1 n\left(Y_{i t}\right)=\ln \beta_{0}+\beta_{1} 1 n\left(X_{1} i t\right)+\beta_{2} 1 n\left(X_{2} i t\right)+\varepsilon i t \\
1 n\left(Y_{i t}\right)=\alpha+\beta_{1} 1 n\left(X_{1} i t\right)+\beta_{2} 1 n\left(X_{2} i t\right)+\varepsilon i t
\end{gathered}
$$

$\ln \beta_{0}=a=$ intercepto;

$\ln \left(Y_{i t}\right)=$ logaritmo natural da proporção de pobres do município $i$ no tempo $t$;

$\ln \left(X_{i} i t\right)=$ logaritmo natural da renda média domiciliar per capita do estado $i$ no tempo $t$;

$\ln \left(X_{2} i t\right)=$ logaritmo natural do Índice de Gini do município $i$ no tempo $t$.

$\beta_{1}=$ elasticidade renda da pobreza; $i=$ municípios $(1, \ldots, 12) ; t=$ anos $(1991,2000$ e 2010).

$\beta_{2}=$ elasticidade desigualdade da pobreza; i=municípios $(1, \ldots, 12) ; \mathrm{t}=$ anos $(1991,2000$ e 2010).

عit= termo erro estocástico

Nesse modelo, a forma funcional log-log implica que o coeficiente angular $\beta$ 's sejam a medida da elasticidade de $Y$ em relação a $X_{1}$ e $X_{2}$, ou seja, as elasticidades da pobreza em relação à renda per capita média e ao índice de Gini, respectivamente.

O coeficiente linear $\alpha$, por sua vez, representa o intercepto da reta de regressão, marcando o ponto onde ela cruza o eixo das ordenadas. Teoricamente, espera-se que, para um aumento da renda, ocorra uma redução da pobreza e, portanto, o coeficiente $\beta_{1}$ deve ser negativo, ao passo que para uma diminuição da desigualdade, ocorra uma redução da pobreza e, portanto, o coeficiente $\beta_{2}$ deve ser positivo.

A regressão da proporção de pobres contra apenas duas variáveis, a renda per capita média e o índice de Gini, justifica-se pelo seu alto poder explicativo e devido à tradicional divisão que a literatura sobre redução da pobreza faz entre o 'efeito crescimento' e o 'efeito distribuição' (PINTO; OLIVEIRA, 2010).

\section{ANÁLISE DOS RESULTADOS E DISCUSSÕES GERAIS}

É fato consagrado na literatura econômica que tanto o crescimento econômico, quanto a desigualdade expressam forte relação com a pobreza, seja em qual for o sentido daquela relação. Dessa forma, a análise de correlação tomou por base as proxies da tríade do desenvolvimento econômico, renda per capita média; índice de Gini e proporção de pobres.

Lembrando que, na análise de correlação, as medida de intensidade da associação entre as variáveis, apresenta-se sempre dentro do intervalo [-1 e +1]. Portanto, a matriz dispostas na Tabela 4, apresenta os resultados da correlação entre os indicadores da tríade do desenvolvimento econômico, conforme pode ser observada a seguir: 
Tabela 4- Matrizes de Correlações das Variáveis (na base log)

\begin{tabular}{|c|c|c|l|}
\hline I_Proppobres & I_Rendapercapita & I_IndicedeGini & \multicolumn{2}{c}{ VARIÁVEIS } \\
\hline 1,0000 & $\mathbf{- 0 , 9 3 2 9}$ & $\mathbf{- 0 , 5 2 6 4}$ & I_Proppobres \\
\hline & 1,0000 & $\mathbf{0 , 6 8 9 2}$ & I_Rendapercapita \\
\hline
\end{tabular}

Fonte: Resultados do Gretl com base nos dados dos Censos Censitários.

Coeficientes de correlação, usando todas as observações e 5\% valor crítico (bicaudal) $=0,3291$ para $n=36$.

Com base nos resultados dispostos na Tabela 4, a correlação entre a proporção de pobres e a renda per capita apresentou-se de forma negativa na ordem de $-0,9329$. 0 sinal desta correlação está concatenada com a teoria econômica, a qual sugere em seu arcabouço que 0 crescimento econômico com qualidade é aquele que tende a reduzir a pobreza.

A correlação entre a proporção de pobres e 0 índice de Gini e entre a renda per capita e 0 índice de Gini apresentaram-se de formas negativa e positiva, nas ordens de -0,5264, e 0,6892, respectivamente. 0 sinal daquelas correlações evidenciam uma suposta discordância teórica, pois, conforme 0 arcabouço da teoria econômica, a pobreza caminha positivamente correlacionada com a desigualdade e, ambas se correlacionam de forma negativa com 0 crescimento econômico. Contudo, os resultados destas correlação sugerem o inverso.

Os resultados da estimação das elasticidades foram realizados por meio da modelagem econométrica seguindo a descrição: modelo linearizado sob a forma log-log com parâmetros estimados pelo método dos mínimos métodos Quadrados Ordinários (MMQO) com a Proporção de Pobres (PropPobres) sendo a variável dependente e; a Renda per capita média (Rendapc) e o Índice de Gini (Gini) como as variáveis explicativas do modelo:

$$
\begin{gathered}
\operatorname{1n}\left(Y_{i t}\right)=\beta_{0}+\beta_{1} 1 n\left(X_{1} i t\right)+\beta_{2} 1 n\left(X_{2} i t\right)+\varepsilon i t \\
\text { InPropPobres }=\beta_{0}+\beta_{1} \ln Q \text { Rendapc }+\beta_{2} \text { lnGini }+ \text { eit }
\end{gathered}
$$

Onde:

1n $\left(Y_{i t}\right) \equiv$ InPropPobres: Proporção de pobres na base log natural, variável dependente;

In $\left(X_{1} i t\right) \equiv$ InRendapc: Renda per capita na base log natural, variável explicativa;

In $\left(X_{2} i t\right) \equiv$ InGini: Índice de Gini na base log natural, variável explicativa;

$\beta_{0}, \beta_{1}$ e $\beta_{2}$ : são os parâmetros dos X's (variáveis explicativas) no modelos.

$\varepsilon_{i t}$ Termo de erro aleatório;

Os resultados da estimação do modelo de regressão, estão dispostos na Tabela 5:

\begin{tabular}{|c|c|c|c|c|c|c|}
\hline Modelo & \multicolumn{2}{|c|}{ MQO Agrupado (Pooled) } & \multicolumn{2}{|c|}{ Efeitos Fixos (EF) } & \multicolumn{2}{|c|}{ Efeitos Aleatórios (EA) } \\
\hline $\begin{array}{c}\text { VARIÁVEIS } \\
\text { EXPLANA- } \\
\text { TÓRIAS }\end{array}$ & $\begin{array}{l}\text { Coeficientes } \\
\text { (Erro Padrão) }\end{array}$ & $\begin{array}{c}\text { Estatística } t \\
\text { (p valor) }\end{array}$ & $\begin{array}{l}\text { Coeficientes } \\
\text { (Erro Padrão) }\end{array}$ & $\begin{array}{c}\text { Estatística } t \\
\text { (p valor) }\end{array}$ & $\begin{array}{l}\text { Coeficientes } \\
\text { (Erro Padrão) }\end{array}$ & $\begin{array}{c}\text { Estatística } t \\
\text { (p valor) }\end{array}$ \\
\hline Intercepto & $\begin{array}{c}7,42350 \\
(0,289728) \\
\end{array}$ & $\begin{array}{c}25,62 \\
2,34 \mathrm{e}-023^{* * *}\end{array}$ & $\begin{array}{c}7,96319 \\
(0,306904) \\
\end{array}$ & $\begin{array}{c}25,95 \\
5,44 \mathrm{e}-018^{\star * *}\end{array}$ & $\begin{array}{r}7,49178 \\
(0,286069) \\
\end{array}$ & $\begin{array}{c}26,19 \\
1,17 \mathrm{e}-023^{\star * *}\end{array}$ \\
\hline In Rendapc & $\begin{array}{c}-0,586830 \\
(0,0418435)\end{array}$ & $\begin{array}{c}-14,02 \\
1,85 \mathrm{e}-015^{* * *}\end{array}$ & $\begin{array}{c}-0,693205 \\
(0,0482387)\end{array}$ & $\begin{array}{c}-14,37 \\
1,16 \mathrm{e}-012^{\star * *}\end{array}$ & $\begin{array}{r}-0,601134 \\
(0,0420237) \\
\end{array}$ & $\begin{array}{c}-14,30 \\
1,05 e-015^{\star * *}\end{array}$ \\
\hline
\end{tabular}

Tabela 5- Resultados do MMQO e teste e da significância das variáveis do modelo 
Fonte: Resultados do Gretl com base nos dados dos Censos Censitários.

Coeficientes das variáveis explicativas significantes à ${ }^{*} 0,10 p ;{ }^{* *} 0,05 p$ e ${ }^{* *} 0,01 p$.

O diagnóstico e painel do Gretl para decisão do modelo apresentou-se:

a) pela Significância conjunta da diferenciação das médias de grupo, $F(11,22)=2,44839$ com p-valor 0,0355263, contrariando a hipótese nula de que o modelo MQO agrupado (pooled) é adequado, validando a hipótese alternativa da existência de efeitos fixos.

b) Pelo teste de Breusch-Pagan (BP), LM = 0,225837 com p-valor = prob (qui-quadrado(1) $>0,225837$ ) $=0,634628$ contrariando a hipótese nula de que o modelo MQO agrupado (pooled) é adequado, validando a hipótese alternativa da existência de efeitos aleatórios.

c) Já no teste de Hausman, a estatística de teste foi de $\mathrm{H}=13,7637$ com $p$-valor = prob (qui-quadrado(2) > 13,7637) $=0,00102624$ contrariando a hipótese nula de que o modelo de efeitos aleatórios é consistente, e assim, validando a hipótese alternativa da existência do modelo de efeitos fixos. Isso significa que, de forma geral, os coeficientes de efeitos fixos são, além de não viesados e consistentes, os mais eficientes para estimação do modelo proposto no estudo. Logo, apresenta-se a seguinte equação de regressão estimada:

É importante atentar para o sinal dos coeficiente da regressão, da renda per capita (Rendapc) e do índice de Gini (Gini), os quais apresentaram, na equação estimada, sinais consistentes com a especificação do modelo teórico, demonstrando a existência de uma relação na análise log-log, inversa da renda per capita (Rendapc) em relação a Proporção de Pobres (PropPobres) e; direta do índice de Gini (Gini) em relação a Proporção de Pobres (PropPobres). Ou seja, quando o indicador de renda variar de forma positiva, este influência de forma negativa na variação do indicador correspondente a proporção de pobres, ao passo que, quando um indicar variar de forma negativa, este influência de forma positiva na variação do outro indicador respectivamente.

A interpretação daqueles coeficientes, sugeriram que: i) o aumento de 1 unidade da quantidade da renda per capita (Rendappc) diminui, em 0,69\% a variação da proporção de pobres (PropPobres), além de prevalecer um impacto negativo na relação entre variáveis; ii) 0 aumento de 1 unidade no índice de Gini (Gini) impactou, em 0,42, a variação da proporção de pobres (PropPobres) além disso, prevaleceu a existência de um impacto positivo na relação entre variáveis. Portanto, a estimação dos coeficientes do modelo descrito na equação (1), com base nos seus parâmetros $(\beta \mathrm{s})$ indicaram possíveis evidências de que o crescimento econômico tem gerado um diminuição da pobreza no curto prazo, porém, este crescimento não pode ser considerado como Pró-pobre. Além disso, no curto prazo, políticas de combate à pobreza com 
foco no crescimento econômico tem maior poder de influência do que às de desigualdade, devido à baixa renda média da população na RIBA em relação à média do estado do Pará e do Brasil.

Ainda com base na Tabela 5 , teste de significância individual para as variáveis do modelo, considerando o $t$ crítico com $99 \%$ de nível de confiança e 1\% de margem de erro e, considerando também as seguintes hipóteses: $H_{0}: \beta 1=\beta 2=0$ e $H_{1}: \beta 1$ e $\beta 2 \neq 0$, temos que com 34 graus de liberdade, percebe-se, , que todas variáveis explicativas do modelo são significante ao nível de $99 \%$ confiança, pois para todas as variáveis, a estatística $t_{\text {calculado }}>t_{\text {tabelado }}\left(t \beta_{0}=25,95\right.$; $\left.t \beta_{1}=14,37 ; t \beta_{2}=2,980>t_{\text {tabelado }}=2,728\right)$. Logo rejeita a hipótese nula, concluindo que todas as variáveis explicativas do modelo - renda per capita (Rendapc) e índice de Gini (Gini), são estatisticamente significativas para explicar a variável dependente, proporção de pobres (PropPobres) a um nível de significância $\leq 1 \%$.

Para testar a significância global do modelo, foram utilizados os testes do $R^{2}$ e o Teste $F, \mathrm{e}$ seu respectivo $p$-valor. Os resultados destes testes podem ser observados na Tabela 6:

Tabela 6- Testes de Significância Global do Modelo pelo MMQO

\begin{tabular}{|c|c|c|c|}
\hline Testes & $\mathbf{R}^{2}$ & $F(2,33)$ & P-valor (F) \\
\hline Valores da Estimação & 0,896141 & 142,3685 & $5,91 \mathrm{e}-17$ \\
\hline
\end{tabular}

$\mathrm{Na}$ análise da significância global do modelo, pelo critério do $R^{2}=0,896141$, ou seja, podemos afirmar que, aproximadamente $89,61 \%$ das variações na variável dependente proporção de pobres (PorpPobres) são explicadas pelas variáveis independentes do modelo, Renda per capita (Rendpc) e índice de Gini (Gini).

Testando a significância pelo critério do teste $F$, para $F$ tabelado em $99 \%$ de margem de confiança e 1\% de margem de erro, e considerando também $F$ de Significância: $F(2,33)=$ 142,3685 e P-valor $(F)=5,91$ e-17, cujas hipóteses são: $H_{0}: \beta 1=\beta 2=0$ e $H_{1}: \beta 1$ e $\beta 2 \neq 0$. Temos, portanto, que o $F$ calculado $(142,3685)$ é maior que $F$ tabelado $(6,24785)$, logo rejeita-se a hipótese nula, o modelo é estatisticamente significativo para explicar a variável dependente, a um nível de significância de $\leq 1 \% .^{9}$

$\mathrm{Na}$ análise de regressão, o objetivo não é apenas o de obter as estimativas de $\beta$, mas também 0 de tecer inferências relativas aos verdadeiros valores dos parâmetros populacionais. Assim, algumas premissas ${ }^{10}$ feitas quanto à(s) variável(is) $X_{i}$ e ao termo de erro são

\footnotetext{
${ }_{9}^{9}$ Assim como no teste $t$, podemos observar diretamente no p-valor do teste $F$, onde neste modelo o mesmo é significante para explicar a variável dependente ao nível de significância de $\leq 1 \%$, pois 5,91e-17 é $<0.01$.

10 Descritas em Gujarati (2006, p. 53-60).
} 
fundamentais para a interpretação das estimativas da regressão. Para testar a violação dos pressupostos básicos do modelo da regressão (3) foram utilizados os seguintes testes: normalidade dos resíduos, não linearidade (logaritmo), especificidade - pelo critério Ramsey/Reset, heterocedasticidade - pelo critério de White e autocorrelação - pelo critério de Durbin-Watson. Os resultados calculados, para aqueles testes, estão descritos na Tabela 7:

Tabela 7- Resultados dos Testes de Violação dos Pressupostos do MMQO
\begin{tabular}{c|c}
\hline TESTE & $\boldsymbol{p}$-valor \\
\hline Especificidade de Ramsey/Reset & 0,342214 \\
\hline Não-Linearidade (Logaritmo) & 0,369089 \\
\hline Normalidade & 0,00532809 \\
\hline Heteroscedasticidade de White & 0,005767 \\
\hline Autocorrelação - Durbin-Watson (p-valor) & $1,04642(0,12041)$ \\
\hline Fonte: Resultados do Modelo com base nos dados Secundários
\end{tabular}

No teste para especificação do modelo, pelo critério de Ramsey/Reset, considerando, $\mathrm{H}_{0}$ : A especificação é correta e $H_{a}$ : A especificação é incorreta com valor-p de 0,342214, desse modo, aceita a hipótese nula, ou seja, a especificação está correta.

No teste da não-linearidade entre as variáveis, sob a forma de logaritmo com $p$-valor = 0,369089. Portanto, como o resultado é estatisticamente significante, aceita a hipótese nula, ou seja, a relação é linear entre as variáveis.

No teste de normalidade dos resíduos, considerando $\mathrm{H}_{0}$ : $\mathrm{O}$ erro tem distribuição normal $\mathrm{e}$ $\mathrm{H}_{\mathrm{a}}$ : O erro não se distribui normalmente, com o $\mathrm{p}$-valor $=0,00532809$ rejeita-se a hipótese nula, ou seja, o erro tende a não se distribuir normalmente.

Para testar a presença de perturbações não-esféricas no modelo, faz-se o teste de White para detectar o problema de heterocedasticidade, considerando, $\mathrm{H}_{0}$ : não existência de heteroscedasticidade e $\mathrm{H}_{a}$ : Existência de heteroscedasticidade. Estatística de teste: $\mathrm{LM}=$ 33,3831, com p-valor $=0,005767$, rejeita-se a hipótese nula, da não existência de heterocedasticidade, em outras palavras, há uma grande dispersão nos dados apresentados.

Para testar a presença de autocorrelação - correlação entre integrantes da série de observações ordenados no tempo, considerando as seguintes hipóteses para a estatística $d$ de Durbin-Watson, $\mathrm{H}_{0}$ : ausência autocorrelação positiva; $\mathrm{H}_{0 *}$ : ausência autocorrelação negativa e

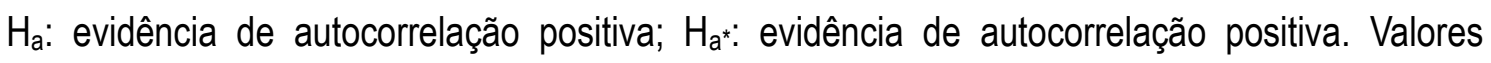
críticos a $5 \%$ para a estatística de Durbin-Watson, com $n=36$ e $k=2$ e $d_{\text {calculado }}=1,04642$ ( $p$ valor $=0,12041)$, com $d_{L}=1,3537 ; d_{U}=1,5872$. Considerando a regra de decisão disposta pela estatística $d$ de Durbin-Watson, temos que: Se $\boldsymbol{d}<\mathrm{dL}<\mathrm{dU}$, ou seja, $\boldsymbol{d} 1,04642<\mathrm{dL}=1,3537<$ $1,52303 \leq \mathrm{dU}=1,5872$, rejeita-se as hipóteses nulas $\left(\mathrm{H}_{0^{*}} \mathrm{e} \mathrm{H}_{0^{*}}\right)$ portanto há possível evidência de 
autocorrelação positiva nos resíduos estimados.

A hipótese da ausência da autocorrelação do modelo clássico refere-se aos termos de erro da população, ut, que não são observados diretamente. 0 que temos são suas proxies, os resíduos $\widehat{u_{t}}$, que podem ser obtidos pelo procedimento habitual dos MQO. Embora os $\widehat{u_{t}}$ não sejam a mesma coisa que ut, muitas vezes um exame visual dos $\widehat{u_{t}}$ dá algumas pistas sobre a provável presença de autocorrelação dos $\widehat{u_{t}}$.

Existem várias maneiras de analisar os resíduos, Gujarati (2006) apresenta dos métodos, que são: a) a princípio, podemos apenas plotar os $\widehat{u_{t}}$ contra 0 tempo, a chamada plotagem sequencial no tempo, ou; b) alternativamente, podemos plotar os resíduos padronizados contra 0 tempo. Os resíduos padronizados são simplesmente os resíduos $\widehat{u_{t}}$ divididos pelo erro padrão da regressão $\left(\sqrt{\widehat{\sigma^{2}}}\right)$, isto é, $\left(\widehat{u_{t}} / \hat{\sigma}\right)$. Observe que $\widehat{u_{t}}$ e $\hat{\sigma}$ são medidos na mesma unidade em que 0 regressando $Y$. Os valores dos resíduos padronizados, portanto, serão números puros (sem unidade de medida) e podem ser comparados com os resíduos padronizados de outras regressões. Além disso, os resíduos padronizados, como $\widehat{u_{t}}$, têm média zero e uma variância aproximadamente unitária. A seguir, na figura 2, encontra-se as devidas plotagens dos resíduos.

De maneira diferente da análise gráfica realizada na plotagem sequencial dos resíduos normais, padronizados, segundo Gujarati (2006, p. 374) "podemos plotar $\widehat{u_{t}}$ contra $\widehat{u_{t-1}}$, isto é, os resíduos no período $t$ contra seu valor em $(t-1)$, uma espécie de teste aplicado do processo $A R(1)$ ". O resultado dos testes de plotagem residual encontra-se na Figura 2:

Figura 2- Plotagem Sequencial dos Resíduos Normais, Padronizados e Defasados no tempo 

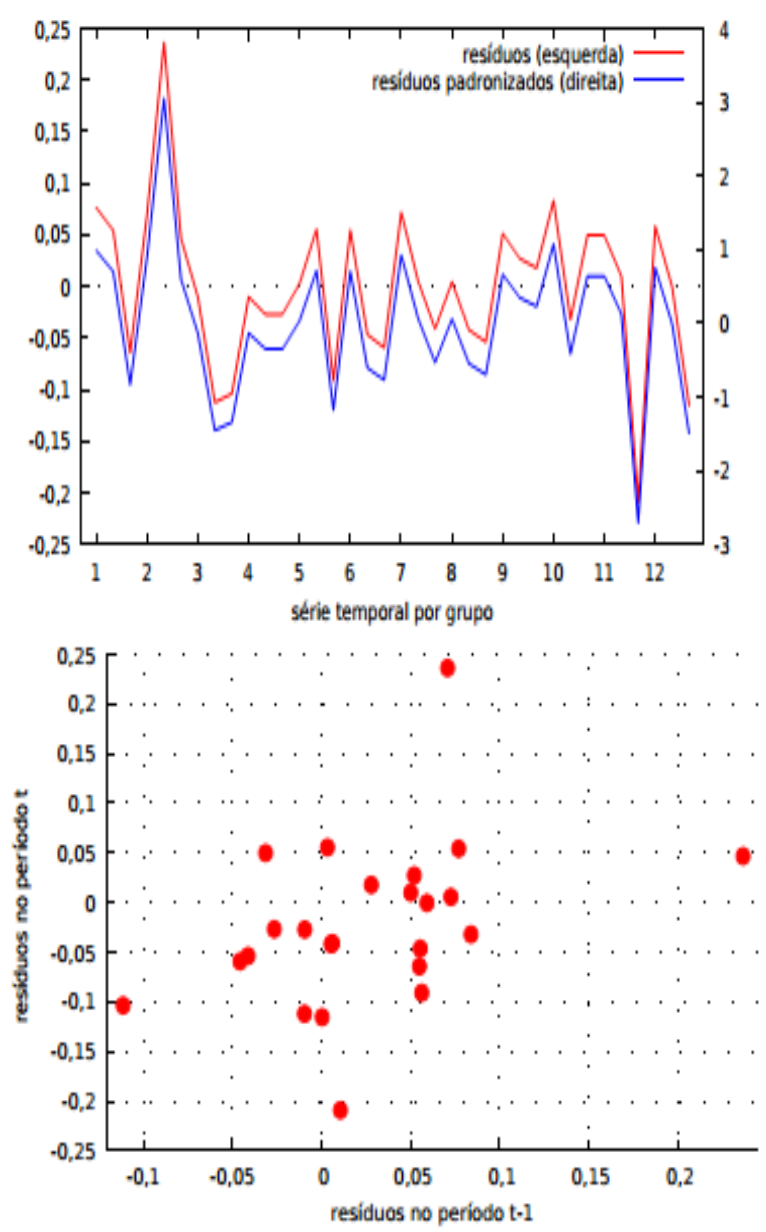

Fonte: Resultados do Gretl com base nos dados dos Censos Censitários.

Examinando a plotagem sequencial dos resíduos normais e padronizados, dispostos na Figura 2, observamos que tanto $\widehat{u_{t}}$ quanto os $\widehat{u_{t}}$ padronizados exibem uma ausência de padrão nos resíduos, sugerindo que os ut sejam aleatórios. Supondo que o termo do erro seja gerado pelo seguinte mecanismo, descrito em Gujarati (2006, p. 363):

$$
u_{t}=\rho u_{t-1}+\varepsilon_{t}
$$

em que $\rho$ é conhecido como coeficiente de autocovariância e $\varepsilon_{t}$ é o termo de erro estocástico tal que atenda à hipótese padrão dos $\mathrm{MQO}$, a saber:

$$
\mathrm{E}\left(\varepsilon_{t}\right)=0 ; \operatorname{Var}\left(\varepsilon_{t}\right)=\sigma^{2} \varepsilon \text { e } \operatorname{Cov}\left(\varepsilon_{t}, \varepsilon_{t}+s\right)=0, \text { com } s \neq 0
$$

Um termo de erro com as propriedades anteriores é, frequentemente chamado, na literatura de engenharia, de ruído branco (white noise) (GUJARATI, 2011).

A Equação (6) postula que o valor do termo de erro no período $t$ é igual a $\rho$ vezes o seu valor no período anterior, acrescido de um termo de erro puramente aleatório. Portanto, o esquema (equação 4) é conhecido como processo autorregressivo de primeira ordem de Markov ou, simplesmente, processo autorregressivo de primeira ordem, normalmente designado como $A R(1)$. A denominação autorregressivo é adequada, porque a Equação (6) pode ser interpretada 
como a regressão de ut na sua própria defasagem de um período. Trata-se de primeira ordem, porque ut e o valor imediatamente anterior estão envolvidos; a defasagem máxima é 1 (GUJARATI, 2006).

A Figura 2 - plotagem sequencial dos resíduos no período $t$ e $t-1$, mostra que a maioria dos resíduos agrupa-se de forma dispersa na parte central dos quadrantes, sugerindo assim, ausência de padrão sistemático, ou seja, da não relação, nem positiva e nem negativa, nos resíduos da regressão.

A correção de existência para heteroscedasticidade é dada como medida corretiva, para duas ocorrências: quando $\sigma^{2}{ }_{i}$ é conhecido e para o valor desconhecido. Contudo, a heterocedasticidade não destrói as propriedades de não tendenciosidade e consistência dos estimadores de MQO, entretanto, elimina a eficiência, pois não é apresentado com exatidão os habituais procedimentos de teste de hipóteses. O método de correção para o caso de heterocedasticidade dá-se, também, pela estimação robusta, utilizando o método dos mínimos quadrados ordinários, ou seja, é uma forma de validação junto a heteroscedasticidade. Os erros padrões robustos têm justificativa apenas assintótica (com amostras pequenas) as estatísticas t's obtidas com os erros-padrão robustos não terão distribuição próxima da t, e as inferências não serão corretas e podem ser maiores ou menores que os não corrigidos (GUJARATI, 2006). Os resultados da estimação do modelo de regressão com correção da Heterocedasticidade e Estimação Robusta (LAD), estão dispostos na Tabela 8:

Tabela 8- Resultados dos Modelos com Correção da Heteroscedasticidade e Estimação Robusta

\begin{tabular}{|c|c|c|c|c|}
\hline \multirow{2}{*}{$\begin{array}{c}\text { MODELO } \\
\text { VARIÁVEIS } \\
\text { EXPLANATÓRIAS }\end{array}$} & \multicolumn{2}{|c|}{$\begin{array}{c}\text { Heteroscedasticidade } \\
\text { corrigida } \\
\end{array}$} & \multicolumn{2}{|c|}{$\begin{array}{c}\text { Estimação Robusta (Mínimo } \\
\text { Desvio Absoluto - LAD) }\end{array}$} \\
\hline & $\begin{array}{l}\text { Coeficientes } \\
\text { (Erro Padrão) }\end{array}$ & $\begin{array}{l}\text { Estatística } t \\
\text { (p valor) }\end{array}$ & $\begin{array}{l}\text { Coeficientes } \\
\text { (Erro Padrão) }\end{array}$ & $\begin{array}{l}\text { Estatística } t \\
\text { ( } p \text { valor })\end{array}$ \\
\hline Intercepto & $\begin{array}{c}7,10489 \\
(0,211601)\end{array}$ & $\begin{array}{c}33,58 \\
\left(4,31 \mathrm{e}-027^{\star \star \star}\right)\end{array}$ & $\begin{array}{c}7,96319 \\
(0,306904)\end{array}$ & $\begin{array}{c}25,95 \\
5,44 \mathrm{e}-018^{\star * *}\end{array}$ \\
\hline In Rendapc & $\begin{array}{c}-0,548994 \\
(0,0336843)\end{array}$ & $\begin{array}{c}-16,30 \\
\left(2,39 \mathrm{e}-017^{\star * \star}\right)\end{array}$ & $\begin{array}{l}-0,693205 \\
(0,0482387)\end{array}$ & $\begin{array}{c}-14,37 \\
1,16 \mathrm{e}-012^{* * *}\end{array}$ \\
\hline In Gini & $\begin{array}{c}0,245044 \\
(0,0913057)\end{array}$ & $\begin{array}{c}2,684 \\
\left(0,0113^{\star *}\right)\end{array}$ & $\begin{array}{c}0,428397 \\
(0,143757)\end{array}$ & $2,9800,0069^{* * *}$ \\
\hline R-quadrado centrado & & 0,925084 & & \\
\hline$F(2,33) / p$-valor(F) & & 203,7472 & $(2,69 \mathrm{e}-19)$ & \\
\hline $\begin{array}{c}\text { Normalidade (p-valor) } \\
\mathrm{H}_{0}: \text { o erro tem distribuição Normal }\end{array}$ & \multicolumn{2}{|c|}{$\begin{array}{l}\text { Qui-quadrado(2) = 17,8917 } \\
\text { com p-valor }=0,000130278\end{array}$} & \multicolumn{2}{|c|}{$\begin{array}{l}\text { Qui-quadrado(2) }=14,5419 \\
\text { com p-valor }=0,000695435\end{array}$} \\
\hline
\end{tabular}

Fonte: Resultados do Gretl com base nos dados dos Censos Censitários.

Coeficientes das variáveis explicativas significantes à ${ }^{*} 0,10 p ;{ }^{* *} 0,05 p$ e ${ }^{* * *} 0,01 p$.

A Tabelas 8 referente aos resultados dos modelos com Heteroscedasticidade-corrigida e com Estimação Robusta (Mínimo Desvio Absoluto) mostra que a estatística $T$ ( $p$-valor) do intercepto e da Rendapc sofreram um aumento, oposto do ocorrido com o Gini no modelo de 
Heteroscedasticidade-corrigida. A Estimação Robusta (Mínimo Desvio Absoluto) apresentou valores inferiores das estatísticas T's (p-valor) para o intercepto, a Rendapc e o Gini.

Em síntese depois de realizado as correções do modelo, as interpretações quanto aos coeficientes, sugeriram que 0 aumento de 1 unidade da quantidade da renda per capita (Rendappc) impacta, em 0,548994 e 0,52\% a variação da proporção de pobres (PropPobres), com um impacto negativo na relação entre variáveis. Neste ponto, a relação evidenciada nos resultados condiz com a evidência teórica da relação entre pobreza e crescimento econômico, que em geral, não se pode esperar redução da pobreza absoluta sem um crescimento positivo.

Já um aumento de 1 unidade no índice de Gini (Gini) aumenta, em 0,25 a variação da proporção de pobres (PropPobres) com a presença de um impacto positivo na relação entre as variáveis, no modelo de Heteroscedasticidade-corrigida. Desse modo, dado o caráter teórico da relação direta entre a desigualdade e pobreza, a princípio, evidencia-se que no período analisado aquela relação foi comprovada. Contudo, tal relação não efetivou-se no Modelo com Estimação Robusta (Mínimo Desvio Absoluto), no qual o parâmetro que estima a elasticidade pobreza-desigualdade não apresentou significância estatística, indicando uma possível relação de instrumentalização entre as três variáveis (renda per capita, desigualdade e pobreza), na qual o fenômeno da desigualdade pode apresentar-se como sendo um estágio intermediário da relação entre os fenômenos da pobreza e do crescimento econômico.

\section{CONSIDERAÇÕES FINAIS}

O objetivo desse estudo foi analisar informações sobre a qualidade do crescimento econômico na Região de Integração do Baixo Amazonas, tentando responder em que medida o crescimento econômico tem sido eficaz para reduzir a pobreza e desigualdade nessa área, bem como este crescimento tem se caracterizado como Pró-pobre. Nesse sentido, com base nos dados do Censo dos anos de 1991, 2000 e 2010. Os resultados das elasticidades, mostraram que no geral a relação entre a proporção de pobres e a taxa de crescimento da renda per capita foi positiva durante o período analisado, significando que em média um aumento na renda per capita provocou um elevação no percentual de pobres.

O estudo verificou que no período analisado a Região de Integração do Baixo Amazonas apresentou crescimento da renda per capita. Entretanto, o que se observa quanto à renda da população mais pobre caiu, com destaque para Terra Santa e Santarém e Prainha, devido maior decréscimo, de modo semelhante é verificado nos indicadores de desigualdade, com destaque para município de Terra Santa aconteceu a menor queda percentual, seguido de Santarém e Almeirim, cenário distinto do observado no Brasil. 
De acordo com o índice de desigualdade (Gini) da RIBA ocorreu aumento na desigualdade ao longo dos períodos e tendo variação positiva elevada, se destacando nessa categoria o município de Almeirim. Em relação aos Indicadores de Pobreza, a Região de Integração do Baixo Amazonas apresentou queda no percentual de pobres, se destacando 0 município de Faro, Santarém e Terra Santa que obtiveram maior queda, assim, como menor nível e menor variação de renda per capita média da população pobre, porém em ritmo mais lento que comparado ao Estado do Pará e ao Brasil. No entanto, o município de Santarém apresentou aumento relevante da renda ao longo do período.

O estudo mostra que apesar de se verificar crescimento econômico na Região de Integração do Baixo Amazonas, e que este promova certa redução na pobreza, a renda dos mais ricos cresce em uma proporção maior que a renda dos mais pobres, ou seja, uma elevação inferior ao verificado pela renda dos mais ricos, ocasionando um aumento na desigualdade, contribuindo para um modelo de crescimento concentrador de renda, haja vista que 0 crescimento sem a promoção da igualdade de renda é insuficiente para a redução da pobreza, resultando em ausência de crescimento pró-pobre nos municípios da região.

Portanto, a análise dos indicadores de crescimento, desigualdade e pobreza, produz informações valiosas, possibilitando um leitura dinâmica da RIBA, informando sobre o cenário econômico, e comprovando que os ganhos desse crescimento não beneficiaram todos os segmentos da população. Assim, as autoridades devem fundamentar-se para promover políticas públicas eficientes e permanente ao longo do tempo, ou seja, uma articulação de políticas que melhorem os níveis educacionais, de saúde e do mercado de trabalho, como a criação de novos postos, reduziria os níveis de pobreza, especialmente em sentido multidimensional, e assim, os indivíduos desfrutariam de melhores circunstâncias no padrão de vida.

O desempenho do crescimento econômico em termos de combate à pobreza, a partir da análise do crescimento pró pobre com uso de dados em painel, nas décadas de 1990, 2000 e 2010, mostrou que no geral a relação entre a proporção de pobres e a taxa de crescimento da renda per capita foi positiva, significando que em média um aumento na renda per capita provocou um elevação no percentual de pobres.

Os resultados indicam que no período de 20 anos (1991-2010) o crescimento na RIBA apresentou Elasticidade renda-pobreza de 0,41 ao passo que a Elasticidade desigualdadepobreza foi de 3,32, logo, a elasticidade desigualdade da pobreza teve maior impacto na pobreza do que a elasticidade renda da pobreza, ou seja, dado uma queda de uma unidade percentual na desigualdade a pobreza aumenta em aproximadamente $3,32 \%$ pontos percentuais, comprovando que, de fato, o crescimento na Região de Integração do Baixo Amazonas foi 
desigual entre as duas categorias da distribuição populacional, pobres e ricos, evidenciando que, de forma geral, o crescimento na RIBA foi essencialmente não Pró-pobre.

Cabe ressaltar que, outros métodos podem ser aplicados para se verificar a interação entre os indicadores de crescimento, desigualdade e pobreza, com fins a análise da qualidade daquele primeiro, o crescimento, em relação aos outros dois, desigualdade e pobreza, sobretudo neste último.

\section{REFERÊNCIAS BIBLIOGRÁFICAS}

ARAUJO, Jair Andrade de. Pobreza Desigualdade e Crescimento Econômico: Três Ensaios em Modelos em Painel Dinâmico. Tese (Doutorado) - Universidade Federal do Ceará, Curso de PósGraduação em Economia, Fortaleza, 2009. 101f.

BARRETO, Flavio Ataliba Flexa Daltro. Crescimento econômico, pobreza e desigualdade: o que sabemos sobre eles?. Série Ensaios Sobre Pobreza. Ceará, v. 1, n. 1, p. 1 -18, dez. 2005.

BARROS, Ricardo Paes de; HENRIQUES, Ricardo; MENDONÇA, Rosane. Desigualdade e Pobreza no Brasil: retrato de uma estabilidade inaceitável. Revista Brasileira de Ciências Sociais. São Paulo, v.15 n. 42, fev. 2000.

BEZERRA, Luciane de Araújo; TEJADA, César Augusto Oviedo; SANTOS, Anderson Moreira Aristides dos; JACINTO, Paulo de Andrade. Pró-pobre ou empobrecedor: qual a contribuição do crescimento econômico para Alagoas? Análise. Porto Alegre, v. 21, n. 2, p. 162-174, jul./dez. 2010.

BERARDI, Nicoletta; MARZO, Federica. The elasticity of poverty with respect to sectoral growth in Africa. The Review of Income and Wealth. Copenhagen, v. 63, n.1, 2015.

BRASIL. Relatório Analítico do Território do Baixo Amazonas - Pará. Ministério de Desenvolvimento Agrário - $\quad$ MDA, $2012 . \quad$ Disponível em:< http://sit.mda.gov.br/download/ra/ra018.pdf>. Acesso em: 16 abr. 2017.

COSTA, Eliane Romeiro; MIRANDA, Giovana Guimarães de. Proteção Previdenciária, gênero e renda na idade avançada. Goiás: UFGO. Sociedade e Cultura, Goiânia, v. 2, n. 2, 2008.

DATT, Gaurav; RAVALION, Martin. Growth and Redistribution Components of Changes in Poverty Measures: A Decomposition with Applications to Brazil and India in the 1980s. Journal of Development Economics, v. 38, n. 2, p. 275-295, 1992.

DINIZ, Marcelo Bentes. Contribuições ao Estudo da Desigualdade de Renda entre os Estados Brasileiros. 2005. Tese (Doutorado em Economia), Faculdade de Economia, Universidade Federal do Ceará, Fortaleza.

GODOY, Karine Rosa; RODRIGUES, Rodrigo Viela. Crescimento pró-pobre no Brasil: uma análise do período 2003-13 para os estados brasileiros. Ensaios FEE, Porto Alegre, v. 38, n. 1, p. 185-214, jun. 2017.

GONÇALVES, Margarete Leniza Lopez. Crescimento pró-pobre nos COREDES e municípios gaúchos: uma análise econométrica (2000-2006). Dissertação em Economia do Desenvolvimento. Programa de Pós Graduação em Economia, PUCRS, Porto Alegre: 2010.

GONÇALVES, Michela Barreto Camboim; SILVEIRA NETO, Raul da Mota. Crescimento própobre nos municípios nordestinos: evidências para o período de 1991 -2002. In: Encontro regional de economia do nordeste, 12., 2007, Fortaleza. Anais... Fortaleza, 2007.

GUJARATI; Damodor. N. Econometria Básica. 4 ed. Rio de Janeiro: Elsevier- Campus, 2006.

GUJARATI, Damodar N.; PORTER, Dawn, C. Econometria Básica. 5 ed. Porto Alegre: RS, 2011. 
KAKWANI, Nanak, PERNIA, Enersto. "What is pro-poor growth?". Asian Development Review, v. 16, n. 2, p. 1-22, 2000.

KRAAY, A. When is growth pro-poor? cross-country evidence. International Monetary Fund (IMF), Working Paper n. 04/47, 2004.

KAKWANI, Nanak; KHANDER, Shahid; SON, Hyun. Pró-pobre growth: concepts and measurement with countrycase studies. International Poverty Centre. Working Paper, Brasília, n. 1, p. $1-28,2004$.

MANSO, Carlos Alberto; BARRETO, Flávio Ataliba; TEBALDI, Edinaldo. O desequilíbrio regional brasileiro: novas perspectivas a partir das fontes de crescimento pró-pobre. Revista Econômica do Nordeste, Fortaleza, v. 37, n. 3, p. 307-238, 2006.

NETTO JUNIOR, José Luis da Silva; FIGUEIREDO, Erik. Crescimento pró-pobre no Brasil e nas regiões no período 1987-2007: uma abordagem não paramétrica. Planejamento e Políticas Públicas, Brasília, DF, n. 42, jan./jun. 2014.

PARÁ. Fundação Amazônia de Amparo a Estudos e Pesquisas (FAPESPA). Diagnóstico Socioeconômico e Ambiental da Região de Integração do Baixo Amazonas. Belém, 2017.

Disponível em: <http://fapespa.pa.gov.br>. Acesso em: 16 jun. 2017.

PERNIA, Ernesto M. Pro-poor Growth: what is it and How is it Important?. Manila, Filipinas: Asian Development Bank, ERD Policy Brief Series, n. 17, 2003.

PINTO, Mauricio Silveira; OLIVEIRA, Julio Cesar de. Crescimento pró-pobre: análise dos estados brasileiros entre 1995 e 2007. Revista de Economia Contemporânea. Rio de Janeiro, v. 14, n. 2, p. 327-358, 2010.

PNUD. Atlas do Desenvolvimento Humano no Brasil (2003). Disponível em http://www.pnud.org.br. Acesso em: 28 jan. 2018.

Atlas do Desenvolvimento Humano no Brasil (2013). Disponível em: <http://www.pnud.org.br>. Acesso em: 28 jan. 2018.

OLIVEIRA; Victor Rodrigues de; JACINTO, Paulo de Andrade. Crescimento pró-pobre ou empobrecedor? Uma análise para os estados brasileiros, no período 1995-2011. Nova Economia, Belo Horizonte, v. 25, n.1, p. 161-180. jan/abr, 2015.

RAVALLION, Martin; DATT, Gaurav. When is growth pro-poor? Evidence from diverse experiences of India's states, Policy Research Working Papers, n. 2263, World Bank, 1999.

Why has economic growth been more Pro-poor in some states of India than others? Journal of Development Economics, v. 68, n. 2, p. 381-400, 2002.

RAVALLION, Martin. Growth, inequality and poverty: looking beyond averages. World development. v. 29, n. 11, p. 1803-1815, 2001.

RAVALLION, Martin; CHEN, Shaohua. Measuring pro-poor growth, Economic Letters, v. 78, n. 1, p. 93-99, 2003.

RESENDE, Guilherme Mendes. "O crescimento econômico dos municípios mineiros têm sido pró-pobre?". Nova Economia, Belo Horizonte, v. 18, n. 1, p. 119-154, 2008.

ROCHA, Sônia. Pobreza no Brasil: afinal do que se trata?. $2^{a}$ edição. Rio de Janeiro: FGV, 2003.

SACHS, Ignacy. Desenvolvimento: Includente, Sustentável, Sustentado. Rio de Janeiro: Garamond, 2008.

SANTOS, Maria Helena de Castro; COUTINHO, Marcelo J. V. "Política comparada: estado das artes e perspectivas no Brasil". Revista Brasileira de Informação Bibliográfica em Ciências Sociais, São Paulo, v. 1, n. 54, p. 5-42, 2002.

SANTOS, Wesley Oliveira. CRESCIMENTO PRÓ-POBRE NO BRASIL (1981-2009). In: Encontro de Economia Catarinense, 6., 2012, Joinville/SC. Anais... UNIVILLE, 2012. 
SILVEIRA NETO, Raul da Mota. Crescimento pró-pobre no nordeste do Brasil: uma análise dos períodos (1991-2000 e 2000-2010). Estudos Econômicos, São Paulo, v .44, n. 3, p.497- 526, 2014.

SON, H. H. A note on pro-poor growth. Economic Letters, n. 82, p. 307-314, 2004.

SOUZA, Nali de Jesus. Desenvolvimento econômico. 3 Edição. São Paulo: Atlas, 1997.

THOMAS, Vinod; DAILAMI, Mansoor; DHARESHWAR, Ashok; KAUFMANN, Daniel; KISHOR, Nalin; LÓPEZ, Ramón; WANG, Yan. A qualidade do crescimento. Tradução Élcio Fernandes. São Paulo: Editora UNESP, 2002.

VEIGA, José Eli. Do global ao local. Campinas: Armazém do Ipê, 2005.

2010.

Desenvolvimento sustentável: o desafio do século XXI. Rio de Janeiro: Garamond,

WHITE, Howard; ANDERSON, Edward. Growth versus distribution: does the pattern of growth matter? Development Policy Review, v. 19, n. 3, p. 267-289, 2001.

Recebido para avaliação em Setembro de 2018.

Aceito para publicação em Agosto de 2019. 


\title{
PROGRAMA DE AQUISIÇÃO DE ALIMENTOS E MUDANÇAS LOCAIS: PROCESSO DE TERRITORIALIZAÇÃO DO ASSENTAMENTO ABRIL VERMELHO - SANTA BÁRBARA/PA
}

\section{Resumo}

Esta pesquisa objetivou identificar o processo de formação do Assentamento Abril Vermelho, com ressalva à sua capacidade produtiva, para um possível acesso ao Programa de Aquisição de Alimentos (PAA). A pesquisa baseou-se no método exploratório, com os seguintes instrumentos: pesquisa bibliográfica, coleta de dados em sites oficiais e pesquisa de campo. Quanto à territorialização deste assentamento, a sua localização na Região Metropolitana de Belém, leva a urgência de sua inserção na acumulação capitalista dessa metrópole, o que contribui à desestruturação de suas organizações socioeconômicas. Assim, há necessidade de fortalecimento dessas organizações, para apoio aos produtores na comercialização dos seus produtos, como possibilidade de excluir os atravessadores; além de garantir produção suficiente para o acesso ao PAA. Dessa forma, tal ação romperia a forma individual de comercialização, e, garantiria a possibilidade do acesso ao PAA, que são fatores positivos à territorialização deste assentamento, devido fortalecer a autonomia das famílias assentadas.

Palavras-chave: Agricultura Familiar; PAA; Segurança Alimentar; Território Periurbano.

\begin{abstract}
This research aimed to identify the process of formation of the Abril Vermelho Settlement, with the exception of its productive capacity, for a possible access to the Food Acquisition Program (PAA). The research was based on the exploratory method, with the following instruments: bibliographic research, data collection in official sites and field research. As for the territorialization of this settlement, its location in the Metropolitan Region of Belém, leads to the urgency of its insertion in the capitalist accumulation of this metropolis, which contributes to the disorganization of its socioeconomic organizations. Thus, there is a need to strengthen these organizations, to support producers in the marketing of their products, as a possibility to exclude middlemen; besides guaranteeing sufficient production for access to the PAA. In this way, this action would break the individual way of commercialization, and would guarantee the possibility of access to the PAA, which are positive factors to the territorialization of this settlement, due to strengthening the autonomy of the settled families.
\end{abstract}

Keywords: Family Agriculture; PAA; Food Safety; Peri-urban Territory.

JEL: R58 - Política de Desenvolvimento Regional 